\title{
Comparison of Proximal Remote Sensing Devices for Estimating Physiological Responses of Eggplants to Root-Knot Nematodes ${ }^{\dagger}$
}

\author{
Alex Silva-Sánchez ${ }^{1}$, Julia Buil-Salafranca ${ }^{1}$, Andrea Casadesús Cabral ${ }^{1}$, Naroa Uriz-Ezcaray ${ }^{1}$, \\ Helio Adán García-Mendívil 2, Francisco Javier Sorribas 1,2, José Luis Araus 1,3 and \\ Adrian Gracia-Romero 1,3,* \\ 1 New Perspectives in Environmental Agrobiology, Master's degree in Environmental Agrobiology, Faculty \\ of Biology, University of Barcelona, 08007 Barcelona, Spain; alexsilvasanchez96@gmail.com (A.S.-S.); \\ julia.buil17@gmail.com (J.B.S.); andrea23195@gmail.com (A.C.C.); naroau@gmail.com (N. U.-E.); \\ francesc.xavier.sorribas@upc.edu (F.J.S.); jaraus@ub.edu (J.L.A.) \\ 2 Department of Agri-Food Engineering and Biotechnology, Universitat Politècnica de Catalunya, Esteve \\ Terradas 8, 08860 Castelldefels, Barcelona, Spain; helio.adan.garcia@upc.edu \\ 3 Integrative Crop Ecophysiology Group, Plant Physiology Section, Faculty of Biology, University of \\ Barcelona, 08007 Barcelona, Spain \\ * Correspondence: adriangraciaromero@hotmail.com \\ + Presented at the 3rd International Electronic Conference on Remote Sensing, 22 May-5 June 2018; \\ Available Online: https://sciforum.net/conference/ecrs-3.
}

Published: 23 May 2019

\begin{abstract}
Proximal remote sensing devices are becoming widely applied in field plant research to estimate biochemical (e.g., pigments or nitrogen) or agronomical (e.g., leaf area, biomass, or yield) parameters as indicators of stress. Non-invasive characterization of plant responses allows for the screening of larger populations faster than conventional procedures which, in addition to requiring more time, either imply the destruction of material or are subjective (e.g., visual ranking). This study explores the comparison of a set of remote sensing devices at single-leaf and whole-canopy levels based on their performance in assessing how the eggplant and its yield responds to grafting as a way to tolerate root-knot nematodes. The results showed that whole-canopy measurements, such as the Green Area (GA) derived from the Red-Green-Blue (RGB) images $(r=0.706$ and $p$-value $=$ $\left.0.001^{* *}\right)$ or the canopy temperature $\left(r=-0.619\right.$ and $p$-value $\left.=0.005^{* *}\right)$, outperformed single-leaf measurements, such as the leaf chlorophyll content measured by the Dualex $(r=0.422$ and $p$-value $=0.059$ ) assessing yield. Moreover, other parameters, such as the time required to measure each sample or the cost of the sensors, were taken into account in the discussion. In sum, indices derived from the RGB images demonstrated their robust potential for the assessment of crop status as a lowcost alternative to other more expensive and time-consuming devices.
\end{abstract}

Keywords: proximal remote sensing; eggplants; toot-knot nematodes; single-leaf measurements; canopy measurements; RGB images; Chlorophyll content; leaf temperature

\section{Introduction}

The formulation of remote sensing indices derived from multispectral information is useful to assess plant diseases, detect stress, or predict crop production [1]. Remote sensing techniques are used to monitor and phenotyping of cultivars properly, for instance, the assessment of biomass, water and nutrient status, or pigment content, which allows the practice of precision agriculture. Traditional procedures in plant physiology studies are destructive (i.e., require the harvest of leaves or even the whole plant) and are especially time consuming [2]. The main benefits of using proximal 
remote sensing sensors are that measurements are performed in field conditions precisely, rapidly, and without the need to destroy the plant material [3]. There are several types of sensors based on the spectral reflectance and transmittance of the plants; all can work at leaf scale, such as clip-leaf sensors that optically measures the relative chlorophyll concentration [4], or at canopy scale, such as the Normalized Difference Vegetation Index (NDVI) that is used for measuring biomass estimations [5]. Another approximation would be the canopy temperature measurements that are used for the detection of changes in stomata conductance as a response of water status [6]. However, the acquisition of such devices entails notable economic cost. However, information derived from RedGreen-Blue (RGB) images is presented as an accessible low-cost alternative [7], providing agricultural farmers the tools to predict production and adjust crop needs to crop supplies, allowing them to be precise in their crop management. Moreover, efforts are focused on the development of inexpensive instruments as the MultispeQ, a low-cost device that, in addition to pigment content, provides measures of photosynthetic parameters [8]. Eggplant (Solanum melongena) has received increasing attention in recent years with regard to its phytochemical and nutraceutical components [9]; however, its production is threatened by root-knot nematode (Meloidogyne javanica). Root-knot nematodes are the most important agricultural pest in several tropical and subtropical countries where eggplant is widely cultivated [10]. It causes several root damage, restricting nutrient and water uptake of crops, and, consequently, limits production. A proposed strategy to minimize the nematodes incidence on plant growth and yield is to use resistant and tolerant rootstocks for grafting the eggplants. In this sense, Solanum torvum may represent an adequate choice as rootstock. The aim of the present study was to compare different proximal remote sensing approaches at the plant and single-leaf level to assess the effect on the eggplant when grafted with the tolerant species Solanum torvum. These remote sensing approaches evaluated water status and plant biomass of eggplants grafted in Solanum torvum. The ability to assess differences in the response to the growing conditions and to correlate to final yield was compared and discussed to conclude which proximal sensing approach (multispectral versus RGB-based indices) and at which level (leaf versus whole plant) is the more convenient to assess to what extent ungrafted and grafted eggplant onto S. toryum are stressed by root-knot nematodes. Sensor cost and the sampling procedures required were also compared.

\section{Experiments}

\subsection{Plant material, growing conditions, and data collection}

The experiment was developed in a plastic greenhouse located at the experimental station of Agròpolis (41 ${ }^{\circ} 17^{\prime} 18.1^{\prime \prime} \mathrm{N} 2^{\circ} 02^{\prime} 38.5^{\prime \prime} \mathrm{E}+18 \mathrm{~m}$ above the sea level, approx.) of the Escola Superior d'Agricultura of the Universitat Politècnica de Catalunya (ESAB - UPC), in the municipality of Viladecans (Barcelona, Spain) from March to November 2018. Soil was artificially infested with Meloidogyne incognita in 2014 and cultivated with eggplant, lettuce, melon, tomato, and watermelon over several years. A total of eighty eggplants, forty ungrafted and forty grafted onto the S. torvum $\mathrm{cv}$. Brutus, were transplanted in twenty plots, four plants per plot. The same plots were used each year to know the putative selection of virulent nematode populations after the repeated cultivation of the resistant eggplant rootstock. The nematode population densities in soil at transplanting (Pi) the ungrafted eggplant ranged from 330 to 7584 juveniles $250 \mathrm{~cm}^{-3}$ of soil, and between 8 and 1292 juveniles $250 \mathrm{~cm}^{-3}$ of soil in plots transplanted with the grafted plant. Each plot consisted of four plants, spaced $0.55 \mathrm{~cm}$ apart, each growing under a plastic greenhouse and fertilized by a drip irrigation system. Eggplants were harvested and weighed when fruits reached commercial standards.

Remote sensing evaluations were performed on October 1, 2018 during the practical lessons of the subject of New Perspectives in Environmental Agrobiology class for the Master's degree in Environmental Agrobiology. The measurements were divided as leaf-based and plant-based assessments, and both were conducted from 15:00 to 17:00 h. Measurements at single-leaf level were performed using two different clip sensors. On the one hand, leaf pigment contents were assessed using Dualex leaf-clip portable sensor (Dualex Force-A, Orsay, France), which measures chlorophyll (Chl), flavonoid (Flav), and anthocyanin (Anth) content [11]. In addition, it calculates the nitrogen 
balance index (NBI), which is the ratio Chl/Flav related to the nitrogen and carbon allocation [12]. On the other, the MultispeQ device (Michigan State University, Michigan, USA), controlled by the PhotosynQ platform software [8], is an instrument that combines the functionality of a handheld fluorimeter, a chlorophyll meter, and a bench-top spectrometer. Moreover, it includes sensors of abiotic factors, such as the ambient temperature, relative humidity, barometric pressure, and altitude as well as contactless leaf temperature, leaf angle, and leaf direction. Among all the parameters that were used as estimates, we used the measures of fluorescence base parameters as the quantum yield of photosystem II (PSII) photochemistry $\left(\Phi_{\mathrm{II}}\right)$, the quantum yield of non-photochemical quenching $\left(\Phi_{\mathrm{NPQ}}\right)$, or the quantum yield of other unregulated (non-photochemical) losses $\left(\Phi_{\mathrm{NO}}\right)$, and the relative chlorophyll content (Rel Chl). One RGB picture was taken per plot, holding the camera at $80 \mathrm{~cm}$ above the plant canopy in a zenithal plane and focusing near the centre of each plot. The conventional digital camera used was a Lumix GX7 (Panasonic, Osaka, Japan), a digital, single-lens, mirrorless camera with an image sensor size of $17.3 \times 13.0 \mathrm{~mm}$. Images were taken at 16-megapixel resolution using a $20 \mathrm{~mm}$ focal length. The images were saved in JPEG format with a resolution of $4592 \times 3448$ pixels and were subsequently analysed using the MosaicTool plugin. This software includes a JAVA8 version of Breedpix 2.0 (https://bio-protocol.org/e1488, IRTA, Lleida, Spain) that enables the extraction of RGB indices in relation to different color properties of potential interest [7]. The NDVI was determined at ground level using a portable spectrometer (GreenSeeker handheld crop sensor, Trimble, Sunnyvale, CA, USA) by passing the sensor over the middle of each plot at a constant height of $0.5 \mathrm{~m}$ above and perpendicular to the canopy. Canopy temperature (CT) was measured using a PhotoTempTM MXSTM TD infrared thermometer (Raytek, Santa Cruz, USA), pointing towards the canopy at a distance of $0.5 \mathrm{~m}$ in the opposite direction of the sun. Finally, combined RGB and thermal images were taken using the phone CATS60 (Caterpillar Inc., Deerfield, Illinois, U.S.) and processed with the CeralsMobile with Hue Enhanced Agricultural Temperature (H.E.A.T.) software (https://integrativecropecophysiology.com/software-development/cerealsmobile/, University of Barcelona, Spain).

\section{Results and Discussion}

Grafting did not report any significant differences in the leaf-based measurement; in contrast, a significant effect was found between treatments (ungrafted and grafted) for almost all the whole plant parameters, with the exception of those derived from the thermal camera of the mobile phone, as seen in Table 1. The Meloidogyne nematode damages the plant roots directly due its parasitic activity, causing a negative effect on the absorption of water and nutrient that is exposed as noticeable reduction in growing [13]. Root-knot nematodes did not affect directly the pigment composition of the leaf, as noted with the leaf-based measurements. Nevertheless, because the nematodes affect roots, we expected a sharper nutritional deficit captured by the leaf-based measurements. Chlorophyll readings on the non-grafted plants were slightly lower than the grafted plants (data not shown). However, little impact was noticed in the correlations of the chlorophyll readings and some of the photosynthesis parameters against yield. On one side, chlorophyll readings are a useful screening criterion to detect stress associated effects [14]. Both leaf-clip devices (Dualex and Photosynq) use the same wavelengths to assess chlorophylls (650 and $940 \mathrm{~nm}$ ). Apart from chlorophylls, Dualex also measures other pigments, but no treatment effects were found for these other pigments that did not correlate with yield. Photosynq provides information about photosystems status [8] and the fates of light energy absorbed [15], as the $\Phi_{\mathrm{II}}$, the $\Phi_{\mathrm{NPQ}}$, or the $\Phi_{\mathrm{NO}}$. The combination of those traits could permit a wider assessment of the plant status. The main reason of the lack of statistically differences between grafted and ungrafted eggplants might be attributable to the period during which the measurements were taken, which might have been too late in the phenological cycle of the eggplants. Therefore, the only significant differences reported were in growth. In fact, in previous studies changes in yield of grafted and ungrafted cucumber were related to the relative variation in both chlorophyll refelctance and net photosynthetic rate [16], confirming previous results in which relative dry top weight of cucumber [17] or zucchini-squash biomass [18] was related to relative leaf chlorophyll content measured earlier in the plant-nematode interaction 
and in situations in which root-knot nematode was the main agent of biotic stress. Alternatively, the effect of nematodes in the plant status was mild but accumulative. Moreover, the operator subjectivity in choosing the leaves to be clipped can represent a cause of error. Finally, the major drawback of the leaf-based clip sensors is the time required to take the measurements. This significant time requirement limits their application in large scale studies because an elevated number of replicates is needed to take representative measures of the whole plot variability. In a comparison of both devices, the sampling with the Photosynq is even more complex because it needs to be operated through Bluetooth using a smartphone and takes longer to measure a single leaf. However, in terms of price, Photosynq is much cheaper than the Dualex.

Table 1. Summary of the different sensor/techniques used to assess crop status. Each technique was evaluated in terms of accuracy, sampling difficulty, sampling time, post-processing, and cost. Color intensities correspond to higher or lower evaluation results. Significant differences between grafted and non-grafted plants were tested by one-way analysis of variance. ns, not significant differences. R, correlation with yield.

\begin{tabular}{|c|c|c|c|c|c|c|c|c|}
\hline \multirow{2}{*}{ Level } & \multirow{2}{*}{ Sensor } & \multirow{2}{*}{ Trait } & \multicolumn{2}{|c|}{ Accuracy } & \multirow{2}{*}{$\begin{array}{l}\text { Sampling } \\
\text { difficulty }\end{array}$} & \multirow{2}{*}{$\begin{array}{c}\text { Sampling } \\
\text { time }\end{array}$} & \multirow{2}{*}{$\begin{array}{c}\text { Post- } \\
\text { processing }\end{array}$} & \multirow{2}{*}{ Cost } \\
\hline & & & ANOVA & $\mathbf{R}$ & & & & \\
\hline \multirow{9}{*}{$\begin{array}{l}\text { Leaf- } \\
\text { based }\end{array}$} & \multirow{4}{*}{ Dualex } & Chl & ns & 0.422 & \multirow{4}{*}{ 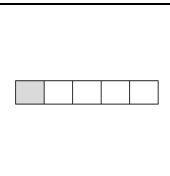 } & & \multirow{4}{*}{\begin{tabular}{|l|l|l|l|} 
& & & \\
\end{tabular}} & \multirow{4}{*}{\begin{tabular}{|l|l|l} 
& $\mid$ &
\end{tabular}} \\
\hline & & Anth & ns & 0.105 & & & & \\
\hline & & Flav & ns & -0.270 & & 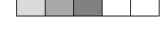 & & \\
\hline & & NBI & ns & 0.277 & & & & \\
\hline & \multirow{5}{*}{ Photosynq } & Phi2 & ns & 0.438 & \multirow{5}{*}{\begin{tabular}{|l|l|l|l|} 
& & & \\
\end{tabular}} & \multirow{5}{*}{\begin{tabular}{|l|l|l|} 
& $\mid$ & \\
\end{tabular}} & \multirow{5}{*}{\begin{tabular}{l|l|l|} 
& $\mid$ & $\square$
\end{tabular}} & \multirow{5}{*}{\begin{tabular}{|l|l|l|l|} 
& & & \\
\end{tabular}} \\
\hline & & PhiNO & ns & -0.169 & & & & \\
\hline & & PhiNPQ & ns & -0.388 & & & & \\
\hline & & Rel Chl & ns & 0.526 & & & & \\
\hline & & $\mathrm{Fv}^{\prime} / \mathrm{Fm}^{\prime}$ & ns & 0.335 & & & & \\
\hline \multirow{12}{*}{$\begin{array}{c}\text { Canopy- } \\
\text { based }\end{array}$} & GreenSeeker & NDVI & $*$ & 0.601 & 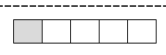 & 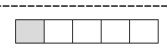 & \begin{tabular}{l|l|l|}
$\square \mid$ & $\mid$
\end{tabular} & \begin{tabular}{|l|l|l|l|} 
& & & \\
\end{tabular} \\
\hline & & Hue & * & 0.662 & \multirow{4}{*}{ 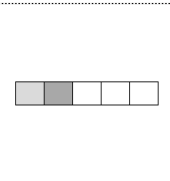 } & \multirow{4}{*}{ 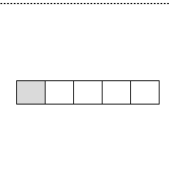 } & \multirow{4}{*}{ 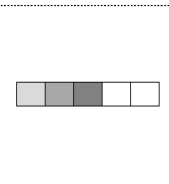 } & \multirow{4}{*}{\begin{tabular}{|l|l|l|l|} 
& & & \\
\end{tabular}} \\
\hline & & GA & $* *$ & 0.706 & & & & \\
\hline & RGB images & GGA & * & 0.635 & & & & \\
\hline & & NGRDI & $* *$ & 0.642 & & & & \\
\hline & Infrared gun & $\mathrm{CT}$ & $* *$ & -0.618 & 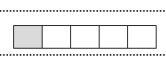 & 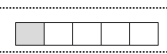 & 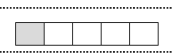 & $\begin{array}{llll}+1 & 1 \\
\end{array}$ \\
\hline & \multirow{6}{*}{$\begin{array}{c}\text { Thermal } \\
\text { camera + RGB }\end{array}$} & Hue & $* *$ & 0.590 & \multirow{6}{*}{\begin{tabular}{|l|l|l|}
$\square$ & & \\
\end{tabular}} & \multirow{6}{*}{\begin{tabular}{l|l|l|} 
& & \\
\end{tabular}} & \multirow{6}{*}{\begin{tabular}{|l|l|}
$\square$ & \\
\end{tabular}} & \multirow{6}{*}{\begin{tabular}{|l|l|l|l|} 
& & & \\
\end{tabular}} \\
\hline & & GA & $*$ & 0.472 & & & & \\
\hline & & GGA & $* *$ & 0.547 & & & & \\
\hline & & $\mathrm{CT}$ & ns & -0.157 & & & & \\
\hline & & CT[GA] & ns & -0.154 & & & & \\
\hline & & CT[GGA] & ns & -0.154 & & & & \\
\hline
\end{tabular}

In contrast, canopy-based measurements presented a better alternative to assess the nematode resistance. The use of RGB indices derived from conventional digital cameras is widely applicable for monitoring crop growth and crop status [19-21]. Via an assessment of the color tonalities of the image with the Hue parameter, the percentage of green pixels can be calculated [7]. GA is the relative amount (in per one) percentage of pixels in the image with a Hue range from $60^{\circ}$ to $180^{\circ}$, including yellow to bluish green color values. Meanwhile, GGA is more restrictive because it reduces the range from $80^{\circ}$ to $180^{\circ}$, thus excluding the yellowish-green tones. The formulation of GA ( $p$-value $<0.001, R$ $=0.706$ ) improved the crop assessment with the Hue parameter itself ( $p$-value $<0.05, R=0.662)$ and the more restrictive index GGA ( $p$-value $<0.05, R=0.635$ ). The GA is a reliable estimation of the crop 
coverage of the soil. Because the eggplants were in a late growing stage, an elevated percentage of leaves were senescent. It was more important to assess differences in growth than the plants that were staying green longer. However, RGB indices derived from the smartphone camera followed a different trend: the Hue values ( $p$-value $<0.001, R=0.590$ ) outperformed GA ( $p$-value $<0.05, R=0.472$ ) and GGA ( $p$-value $<0.001, R=0.547$ ) formulations. This might be attributable to the differences in image resolutions of both devices (digital camera versus phone camera). Using the RGB images, the Normalized Green Red Difference Index (NGRDI) was also calculated, which is an index similar to NDVI but uses information from the green instead of the near-infrared bands. The NDVI is one of the most well-known vegetation indices to assess crop biomass. However, our results showed than even if the Red-Green reflectance break was smaller than the Red-NIR break, the NGRDI ( $p$-value < $0.001, R=0.642$ ) outperformed the NDVI ( $p$-value $<0.05, R=0.601$ ). These results support the conclusion that the indices derived from conventional digital images are efficient and low-cost alternatives when compared with the specialized and more expensive sensors, such as the GreenSeeker. Finally, the canopy temperature ( $p$-value $<0.001, R=-0.618)$ was also assessed, and it was reported as an accurate parameter for determining the crop resistance to the nematode. Decreases in stomatal conductance and transpiration rates as response to water stress cause an increase in plant temperature [22]. Nevertheless, the temperature measurements from the thermal camera of the CATS60 phone failed ( $p$-value $>0.05, R=-0.157$ ). The expected results were the opposite because the CerealApp permits combining a GA and a GGA mask to the thermal camera to achieve an accurate assessment of the temperature of the green area, avoiding noise from the soil that might affect the measurements with the infrared gun.

\section{Conclusions}

Single-leaf measurements did not show significant differences between grafted and non-grafted plants, and their correlations with yield were generally low. Additionally, plant-based measurements showed significant differences between both types of plants and higher yield correlations with yield. These findings suggest that plant-based measurements were more effective in assessing the response of the eggplants to root-knot nematodes. Root-knot nematodes did not affect leaf chlorophylls. Although they are not considered advanced technology, RGB indices reported significant differences between the growing treatments and showed the best correlations with yield. Plant temperature measurements with the infrared thermometer also performed well in assessing differences in terms of plant resistance to the nematodes. It correlated negatively with yield, probably attributable to the fact that the roots less affected by nematodes had better access to water and that stomata conductance was higher. However, when both categories of remote sensing traits (RGB indices and canopy temperature) were measured simultaneously with the same device (smartphone), the results obtained were worse. This can be attributable to the fact that this measurement was taken later and the solar conditions had changed. This clearly illustrates the importance of how and when (during the daytime) the temperature measurements are taken. In conclusion, in terms of measurements at leaf level, both Dualex and Photosynq are two interesting devices to study crops due to their high throughput measuring pigment and photosynthetic data; results could have been better if measured at an earlier phenological stage. Drawbacks of these devices include their time-consuming nature. Furthermore, canopy-based measurements permit the study of the whole plot at once (without the need of replicates) and showed the best results. RGB indices are presented as a promising remote sensing technique due to its user-friendly and low-cost nature. It should be noted that this measurement can be easily taken with a simple smartphone.

Author Contributions: H.A.G.-M. and F.J.S. managed and directed the trial at the experimental station of Agròpolis. J.L.A. and A.G.-R.conceived and designed the experiment. A.S.-S., J.B.-S., A.C.C. and N.U.-E. conducted the field measurements and analysed the data. A.S.-S., J.B.-S., A.C.C., N.U.-E. and AG-R wrote the manuscript, under the supervision of J.LA. and F.J.S.

Acknowledgments: This work was supported by projects AGL2013-49040-C2-1-R, and AGL2017-89785-R funded by MINECO and FEDER. Thanks are given to CONACYT for providing PhD funding to H. A. García- 
Mendívil, to Dr. Shawn C. Kefauver (University of Barcelona) for providing the Cereal Scanner app and the personnel from Agròpolis.

Conflicts of Interest: The authors declare no conflict of interest.

\section{Abbreviations}

RGB: Red-Green-Blue;

GA: Green Area;

GGA: Greener Area;

NDVI: Normalized Difference Vegetation Index;

ESAB-UPC: Escola Superior d'Agricultura of the Universitat Politècnica de Catalunya;

ФII: Quantum yield of photosystem II (PSII) photochemistry;

ФNPQ: Quantum yield of non-photochemical quenching;

ФNO: Quantum yield of other unregulated (non-photochemical) losses;

Rel Chl: Relative chlorophyll content

\section{References}

1. Fiorani, F.; Schurr, U. Future scenarios for plant phenotyping. Annu. Rev. Plant Biol. 2013, 64, $267-291$.

2. Araus, J.L.; Cairns, J.E. Field high-throughput phenotyping : the new crop breeding frontier. Trends Plant Sci. 2014, 19, 52-61.

3. Araus, L.; Kefauver, S.C. Breeding to adapt agriculture to climate change: affordable phenotyping solutions. Curr. Opin. Plant Biol. 2018, 45, 237-247.

4. Dwyer, L.M.; Tollenaar, M.; Houwing, L. A nondestructive method to monitorleaf greenness in corn. Can. J. Plant Sci. 1991, 71, 505-509.

5. Tucker, C.J. Red and photographic infrared linear combinations for monitoring vegetation. Remote Sens. Environ. 1979, 8, 127-150.

6. Deery, D.M.; Rebetzke, G.J.; Jimenez-Berni, J.A.; James, R.A.; Condon, A.G.; Bovill, W.D.; Hutchinson, P.; Scarrow, J.; Davy, R.; Furbank, R.T. Methodology for High-Throughput Field Phenotyping of Canopy Temperature Using Airborne Thermography. Front. Plant Sci. 2016, 7, 1808.

7. Casadesús, J.; Kaya, Y.; Bort, J.; Nachit, M.M.; Araus, J.L.; Amor, S.; Ferrazzano, G.; Maalouf, F.; Maccaferri, M.; Martos, V.; Ouabbou, H.; Villegas, D. Using vegetation indices derived from conventional digital cameras as selection criteria for wheat breeding in water-limited environments. Ann. Appl. Biol. 2007, 150, 227-236.

8. Kuhlgert, S.; Austic, G.; Zegarac, R.; Osei-bonsu, I.; Hoh, D.; Chilvers, M.I.; Roth, M.G.; Bi, K.; Teravest, D.; Kramer, D.M. MultispeQ Beta : a tool for phenotyping connected to the open PhotosynQ network Subject Areas. R. Soc. Open Sci. 2016, 3. doi: 10.1098/rsos.160592.

9. Lo, R.; Fibiani, M.; Francese, G.; Alessandro, A.D.; Rotino, G.L.; Conte, P.; Mennella, G. Cooking influence on physico-chemical fruit characteristics of eggplant (Solanum melongena L.). Food Chem. 2016, 194, 835842.

10. Krysczun, D.K.; Dal, A.; Lúcio, C.; Sari, B.G.; Diel, M.I.; Olivoto, T.; Santana, C.S.; Ubessi, C.; Schabarum, D.E. Scientia Horticulturae Sample size, plot size and number of replications for trials with Solanum. Sci. Hortic.-Amst. 2018, 233, 220-224.

11. Cerovic, Z.G.; Masdoumier, G.; Ghozlen, N. Ben; Latouche, G. A new optical leaf-clip meter for simultaneous non-destructive assessment of leaf chlorophyll and epidermal flavonoids. Physiol. Plant. 2012, 146, 251-260.

12. Cerovic, Z.G.; Ghozlen, N. Ben; Milhade, C.; Obert, M.; Debuisson, S.; Le Moigne, M. Nondestructive Diagnostic Test for Nitrogen Nutrition of Grapevine (Vitis vinifera L.) Based on Dualex Leaf-Clip Measurements in the Field. J. Agric. Food Chem. 2015, 63, 3669-3680.

13. Sorribas, F.; Giné, A. Meloidogyne spp. (Nematodo de los nódulos o agallas de las raíces). In Guía de gestión integrada de plagas para cultivos hortícolas de hoja: espinaca, lechuga, acelga, escarola y borraja; 2017; pp. 131-135. 
14. Giunta, F.; Motzo, R.; Deidda, M. SPAD readings and associated leaf traits in durum wheat, barley and triticale cultivars. Euphytica 2002, 125, 197-205.

15. Monteagudo, A.; Am, C.; Mp, G.; Fj, C.; Boutin, C.; Pa, P.; Igartua, E. Differences in photosynthesis efficiency related parameters in a hybrid-parent barley germplasm set. In proceedings of II Spanish Symposium on Physiology and Breeding of Cereals, Cordoba, Spain, 6-7 March 2019.

16. Giné, A.; González, C.; Serrano, L.; Sorribas, F.J. Population dynamics of Meloidogyne incognita on cucumber grafted onto the Cucurbita hybrid RS841 or ungrafted and yield losses under protected cultivation. Eur. J. Plant Pathol. 2017, 148, 795-805.

17. Gine, A.; Sorribas, F.J. Thermal requirements and population dynamics of root-knot nematodes on cucumber and yield losses under protected cultivation. Plant Pathol. 2014, 63, 1446-1453.

18. López-Gómez, M.; Flor-Peregrín, E.; Talavera, M.; Sorribas, F.J.; Verdejo-Lucas, S. Population dynamics of Meloidogyne javanica and its relationship with the leaf chlorophyll content in zucchini 1 Introduction 2 Materials and methods. Crop Prot. 2015, 70, 8-14.

19. Fernandez-gallego, J.A.; Kefauver, S.C.; Vatter, T. Low-cost assessment of grain yield in durum wheat using RGB images. Eur. J. Agron. 2019, 105, 146-156.

20. Vergara-Díaz, O.; Kefauver, S.C.; Elazab, A.; Nieto-Taladriz, M.T.; Araus, J.L. Grain yield losses in yellowrusted durum wheat estimated using digital and conventional parameters under field conditions. Crop J. 2015, 3, 200-210.

21. Gracia-Romero, A.; Kefauver, S.C.; Vergara-Diaz, O.; Zaman-Allah, M.A.; Prasanna, B.M.; Cairns, J.E.; Araus, J.L. Comparative performance of ground versus aerially assessed RGB and multispectral indices for early-growth evaluation of maize performance under phosphorus fertilization. Front. Plant Sci. 2017, 8, 113.

22. Araus, J.L.; Bort, J.; Steduto, P.; Villegas, D.; Royo, C. Breeding cereals for Mediterranean conditions : ecophysiological clues for biotechnology application. Ann. Appl. Biol. 2003, 142, 129-141. 